\title{
SISTEMA RADICULAR DAS PRINCIPAIS LEGUMINO- SAS EMPREGADAS COMO ADUBO VERDE EM CAFEZAL
}

H. J. Scaranari, engenheiro agrónomo, Seção de Cafe, e R. Inforzato, engenheiro agrónomo, Seçãa de Fisiologia, Instituto Agronómico de Campinas

\section{1 - INTRODUÇÃO}

A adubação dos cafeeiros constitui um dos principais fatôres da manutenção da lavoura em condiçōes de produção econômica. A base dessa adubação é, sem dúvida alguma, a matéria orgânica. Assim é que tôdas as experiências realizadas e em andamento no Instituto Agronômico de Campinas, deram resultados satisfatórios, quando foi empregada a matéria orGânica $(2,5)$.

Diversas são as fontes de matéria orgânica de que se pode lançar mão para sua incorporação aos solos dos cafèzais : estêrco de curral ou de esterqueiras, palha de café, composto, serapilheira de mato e adubos verdes (6).

Infelizmente, as condições nas quais as nossas fazendas de cafe foram formadas, isto $e$, utilizando-se sempre terras virgens, ricas de húmus, fizeram com que a grande maioria dos lavradores não cuidasse da organização necessária à produção da matéria orgânica para manter sempre aquela produtividade inicial dos cafeeiros. Por essa razão, a maior parte das nossas propriedades agrícolas produz diminuta quantidade de estêrco, suficiente para a adubação de sòmente pequena parte de seus cafèzais. Surgem, então, os adubos verdes como fonte da matéria orgânica para a adubação de grande parte dos cafeeiros restantes.

Os resultados que se obtêm com a adubação verde não são imediatos e dependem principalmente do solo em que se situa a lavoura. Se o solo se achar muito esgotado, o emprêgo das leguminosas trará resultados sòmente após vários anos de aplicação. Em terras novas, o efeito se faz sentir mais depressa, principalmente quando se adicionam ao adubo verde partes de adubos minerais ; isto, pelo menos, é o que se deduz dos resultados que estão sendo obtidos no ensaio de adubação instalado na Estação Experimental de Pindorama (5).

De acôrdo com observações feitas até o presente, os adubos verdes aconselhados para cafèzal, são : feijão de porco (Canavalia ensiformis D. C.), Crotalaria juncea L., Mucuna anã (Stizolobium sp) e soja (Glycine max L. var. otootan).

A massa verde produzida por essas leguminosas foi determinada em diversos ensaios instalados pela antiga Secção de Agronomia, e, atualmente, pela Secção de Cereais e Leguminosas do Instituto Agronômico (4, 7). 
A C. juncea é a melhor produtora de massa verde, porém apresenta a desvantagem de não se prestar para a adubação verde de cafèzais novos, pois, além de abafar os cafeeiros com o seu alto porte, é suscetível à murcha causada por Ceratostomella fimbriata (Ell. et Halst.) Elliott (1). O feijão de porco, das leguminosas citadas, é o segundo produtor de massa verde, mas apresenta a desvantagem de ser atacado por uma moléstia de vírus que faz cair a produção de sementes. A mucuna anã e a soja são as de menor produção de massa. Tôdas essas leguminosas são indicadas para a adubação verde, podendo ser empregadas uma ou mais no cafèzal, de acôrdo com a facilidade de obtenção das sementes na época apropriada para a semeação.

$\mathrm{Na}$ adubação verde, além da massa verde produzida pela parte aérea das leguminosas, é de importância a quantidade de raízes produzidas e a sua distribuição nas diferentes camadas do solo. Essas raízes melhoram a textura do solo, aumentam a sua capacidade de retenção das águas pluviais em virtude dos inúmeros canalículos deixados após a sua decomposição, e promovem a translocação dos elementos minerais das camadas mais profundas às camadas superficiais.

Baseando-se nestas considerações, estabeleceu-se o plano para determinação do sistema radicular das leguminosas mais indicadas para aplicação nos cafèzais, cujos resultados est.ão sendo divulgados neste trabalho.

\section{2 - MATERIAL E METODO}

O presente trabalho foi executado no solo tipo terra roxa misturada da Estação Experimental Central de Campinas. Para êste estudo, os adubos verdes foram semeados em canteiros, procurando-se dar os espaçamentos indicados para o plantio no cafèzal. As distâncias entre as linhas foi de $40 \mathrm{~cm}$ e, entre plantas, foram dadas, aproximadamente, as seguintes distâncias : linha cheia para a crotalária; $10 \mathrm{~cm}$ para a mucuna anã, e $5 \mathrm{~cm}$ para a soja e o feijāo de porco. O estudo do sistema radicular do feijão de porco foi executado onde as plantas guardavam $18 \mathrm{~cm}$ em média, de distância entre si.

A técnica empregada foi a mesma usada em trabalhos anteriores sôbre o sistema radicular do cafeeiro (3).

A retirada dos blocos de terra foi feita por camadas. As dimensóes dos blocos, para a crotalária e feijão de porco, foram as seguintes: três camadas de $10 \mathrm{~cm}$ de espessura por $30 \mathrm{~cm}$ de largura e $30 \mathrm{~cm}$ de comprimento; duas camadas de $15 \mathrm{~cm}$ por $30 \mathrm{~cm}$ por $30 \mathrm{~cm}$ e as restantes com $20 \mathrm{~cm}$ por $30 \mathrm{~cm}$ por $30 \mathrm{~cm}$. No estudo da mucuna anã e soja, apenas a largura dos blocos variou para $40 \mathrm{~cm}$.

\section{3 - DADOS OBTIDOS}

\section{1 - FEIJÃO DE PORCO}

Iniciou-se o estudo do sistema radicular do feijão de porco em 11 de março de 1949, quando as plantas, com 110 dias depois da germinação, estavam em adiantado florescimento. 


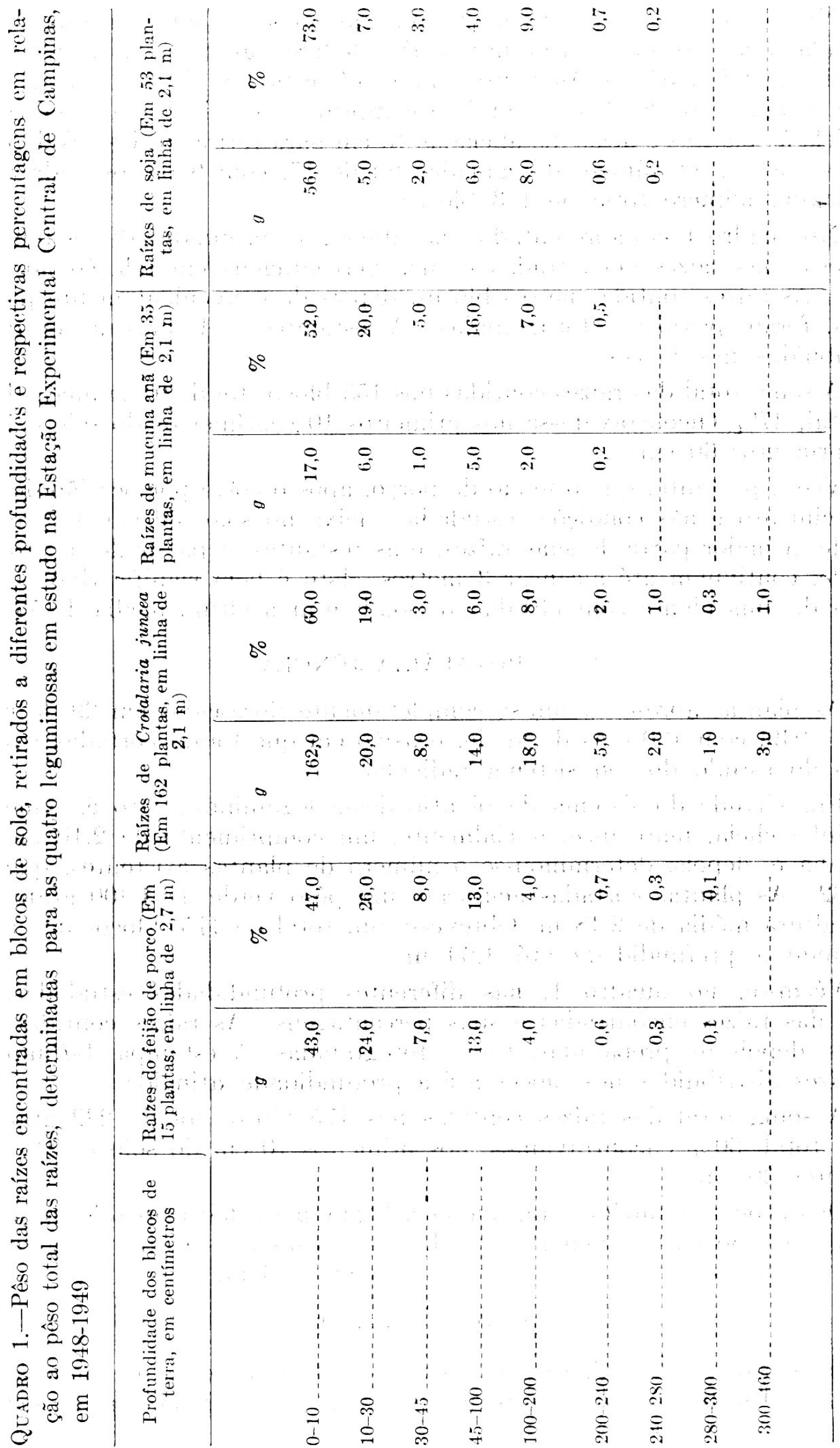


Numa das linhas do canteiro foram marcadas 15 plantas consecutivas. Cortadas rente ao solo, acusaram um pêso de 2.860 gramas. A altura média das plantas foi de $55 \mathrm{~cm}$. As plantas em estudo estavam distribuídas na linha numa extensão de $2,70 \mathrm{~m}$. Com êsse comprimento, foi aberta uma valeta paralela às plantas e delas distanciadas $15 \mathrm{~cm}$ para retirar os blocos de terra com as raízes. O número de camadas foi de 17 , com 9 blocos cada uma, dando um número total de 153 blocos.

No quadro 1 são apresentados, nas diferentes profundidades estudadas, os pesos das raízes encontradas e suas percentagens em relação ao pêso total. As raízes contidas nesses blocos, depois de convénientemente preparadas, foram pesadas e fotografadas. A estampa 1-A mostra as raízes distribuídas nos blocos.

A soma total das raízes contidas nos 153 blocos foi de 91 gramas. Dêste total, $47 \%$ encontravam-se nos primeiros 10 centímetros do solo e $73 \%$ nos primeiros $30 \mathrm{~cm}$.

Vê-se, portanto, que o feijão de porco, após o corte por ocasião do seu florescimento e nas condições estudadas, deixa no solo $(30 \mathrm{~cm}$ de profundidade) a maior parte de suas raízes, e as restantes, a partir desta profundidade, continuam até alcançar 3 metros. Isto é bem significativo por se tratar de uma planta com 110 dias de idade e uma altura média de $55 \mathrm{~cm}$.

\section{2_- CROTALARIA JƯNCEA}

As plantas apresentavam-se completamente florescidas em 29 de março de 1949, com 130 dias de idade, ocasião em que foram cortadas para o início do estudo do seu sistema radicular.

Em virtude do sistema de plantio dessa leguminosa, isto é, semeada em linha cheia, marcou-se, inicialmente, um comprimento de 2,10 metros na linha e, depois, determinou-se o número de plantas existentes, que foi de 162. As plantas cortadas acusaram um pêso verde de 4.400 gramas e uma altura média de $2,18 \mathrm{~m}$. Obteve-se um total de 175 blocos de terra atingindo a profundidade até $4,60 \mathrm{~m}$.

Vêem-se, no quadro 1, nas diferentes profundidades estudadas, os pesos das raízes encontradas e suas percentagens. As raízes contidas nos blocos, depois de preparadas, foram fotografadas. A estampa 1-B mostra as raízes distribuídas nos blocos até a profundidade atingida.

A soma total das raízes contidas nos 175 blocos foi de 232 gramas. Dêste total, $60 \%$ encontravam-se nos primeiros $10 \mathrm{~cm}$ do solo e $78 \%$ nos primeiros $30 \mathrm{~cm}$.

Observou-se também aqui, que esta leguminosa deixa no solo, pròpriamente dito $(30 \mathrm{~cm})$, a maior parte de suas raízes e as restantes, a partir desta profundidade, continuam até alcançar $4,60 \mathrm{~m}$.

\section{3 - MUCUNA ANA}

Iniciou-se a determinação do sistema radicular dessa leguminosa em 6 de março de 1950, quando as plantas estavam com 100 dias, após a semeação. 
A valeta, para a retirada dos blocos, foi aberta distanciada de $20 \mathrm{~cm}$ dos caules das plantas e numa extensão de $2,10 \mathrm{~m}$. As plantas cortadas rente ao solo, foram pesadas, acusando um pêso verde de 1.675 gramas resultantes de 35 plantas, com aliura média de $49 \mathrm{~cm}$.

Após a retirada de 98 blocos, distribuídos em 14 camadas, atingiu-se a profundidade de $2,40 \mathrm{~m}$. No quadro 1, vêєm-se, nas diferentes profundidades estudadas, os pesos das raízes encontradas e suas percentagens. Na estampa 2-A nota-se a distribuição das raízes até a profundidade citada.

A soma total das raízes contidas nos 98 blocos foi de 32 gramas. As raízes estavam distribuídas numa percentagem de $52 \%$ nos primeiros 10 cm do solo, e $72 \%$ nos primeiros $30 \mathrm{~cm}$.

A mucuna anã, após o corte por ocasião do seu florescimento, deixa, pois, nos primeiros $30 \mathrm{~cm}$ do solo, a maior parte de suas raízes e as restantes são distribuídas até atingir $2,40 \mathrm{~m}$ de profundidade.

\section{4 - SOJA OTOOTAN}

O estudo do sistema radicular dessa leguminosa, foi iniciado em 15 de março de 1950, quando as plantas florescidas estavam com 109 dias, a partir da semeação. Esta determinação foi feita numa extensão da linha de plantio, também de $2,10 \mathrm{~m}$, onde estavam distribuidas 53 plantas.

Distante de $20 \mathrm{~cm}$ do caule das plantas, foi aberta a valeta para a retirada dos blocos. As plantas foram cortadas rente ao solo e depois de pesadas acusaram um pêso de 1.030 gramas e uma altura média de $66 \mathrm{~cm}$.

Após a retirada de 112 blocos, distribuídos em 16 camadas, atingiu-se a profundidade de $2,80 \mathrm{~m}$, a partir da qual não mais se encontraram raízes.

Pelo quadro 1 , observam-se, nas diferentes profundidades estudadas, os pesos das raízes encontradas e suas percentagens. A estampa 2-B mostra a distribuição das raízes nas diferentes camadas do solo.

A soma dos pesos das raízes retiradas nas 16 camadas, foi de 77 gramas, distribuídas numa percentagem de $56 \%$, nos primeiros $10 \mathrm{~cm}$ do solo, e $73 \%$ nos primeiros $30 \mathrm{~cm}$.

\section{4 - DISCUSSÃO E CONCLUSÕES}

O estudo do sistema radicular das leguminosas citadas, indicou que a profundidade atingida pelas raízes está relacionada com o desenvolvimento da parte aérea das plantas. Assim é que a maior profundidade atingida e maior massa produzida pelas raízes foi encontrada na Crotalaria juncea, seguindo-se o feijão de porco, soja e mucuna anã. Guardam, pois, estas leguminosas, a mesma ordem de classificação que já haviam obtido quando estudadas sob o aspecto de massa verde produzida e altura média das plantas.

Verificou-se, também, ser pequena a quantidade de matéria orgânica deixada no solo pelas raízes, quando comparada com a que é produzida pela parte aérea. No entanto, sua ação é extremamente importante, pois 
que de outra forma nunca se conseguirá colocar tão precioso elemento em camadas tão profundas. Com isto, há um melhoramento apreciável das propriedades físicas do solo.

Observou-se que, nas quatro leguminosas estudadas, a maior parte das raízes se encontra nos primeiros 30 centímetros do solo. Este fato tem importância na cultura do cafeeiro, cujo sistema radicular se encontra quase totalmente nessa mesma camada. Poder-se-ia concluir, dai, haver uma concorrência entre a planta utilizada como adubo verde e o cafeeiro. Tal não se dá, porque o plantio da leguminosa é sempre feito no período chuvoso e o corte por ocasião do florescimento. Nesse periodo, há água suficiente no solo para ambos. Depois de cortado, o apodrecimento de apreciável quantidade de raízes da leguminosa na camada em que o cafeeiro possui maior possibilidade de se alimentar, proporcionará mais fàcilmente elementos para isso.

\section{SLMMARY}

Root systems of the following leguminous plants used for green manure in colfee plantations werc studied : Canqualia ensiformis D. C., Crotalarir juncea $\mathbf{L}$,. Styzolobium sp (Mucuna añ̃) and Glycine max (L). Merrill var. Otootan. It was noted that the depth of the root systen of exch one of the four especies is related to the height attained by the planty. The decpest root system wis found to be that of Crotdiaria juncea, followed by Canavalide ensifornis, soybehns and macuina añ

For coffes green manure purposes it is concluded that the four studied leguminous especies equ be used safoly even having mast of their root system located in the first $30 \mathrm{~cm}$ of the sojil.

\section{LITERATURA CITADA}

1. Costa, A. S. e'H. P. Krug. Eine durch Ceratostomella hervorgerufene Welkekrankheit der Crotalaria juncea in Brasilien. Phytopath. Z. 8 : 507-513. 1935.

2. Dafert, F. W. Experiências sôbre estrumą̧ão. Relat. Inst. agron. Campinas 17 (1892-1893) : 202-216." 1895.

3. Franco, C. M. e R. Inforzato. $O$ sistema radicular do cafeeiro nos principais tipos de solo do Fstado de São Paulo. Bragantia 6 : 443-458. 1946.

4. Martins, R. Cruz. Em Relat, Inst. agron, Campinas 1929-30 : 114-130. 1935.

5. Mendes, J. E. T. Em Relat. Secção Café Inst. agron. Campinas. 1942 : 17-21 (Não publicado).

6. Mendes, J. F. T. Adubação verde para cafèzais. Sep. 'Bol. Suptda Serv. :Cafe, S. Paulo, 1-15. 1950

7. Neme, Neme A. $E m$ Rel. Seç̧ẩo Cercais e Leguminosas, Inst. agron. Campinas 1951. (Nao publicado). 

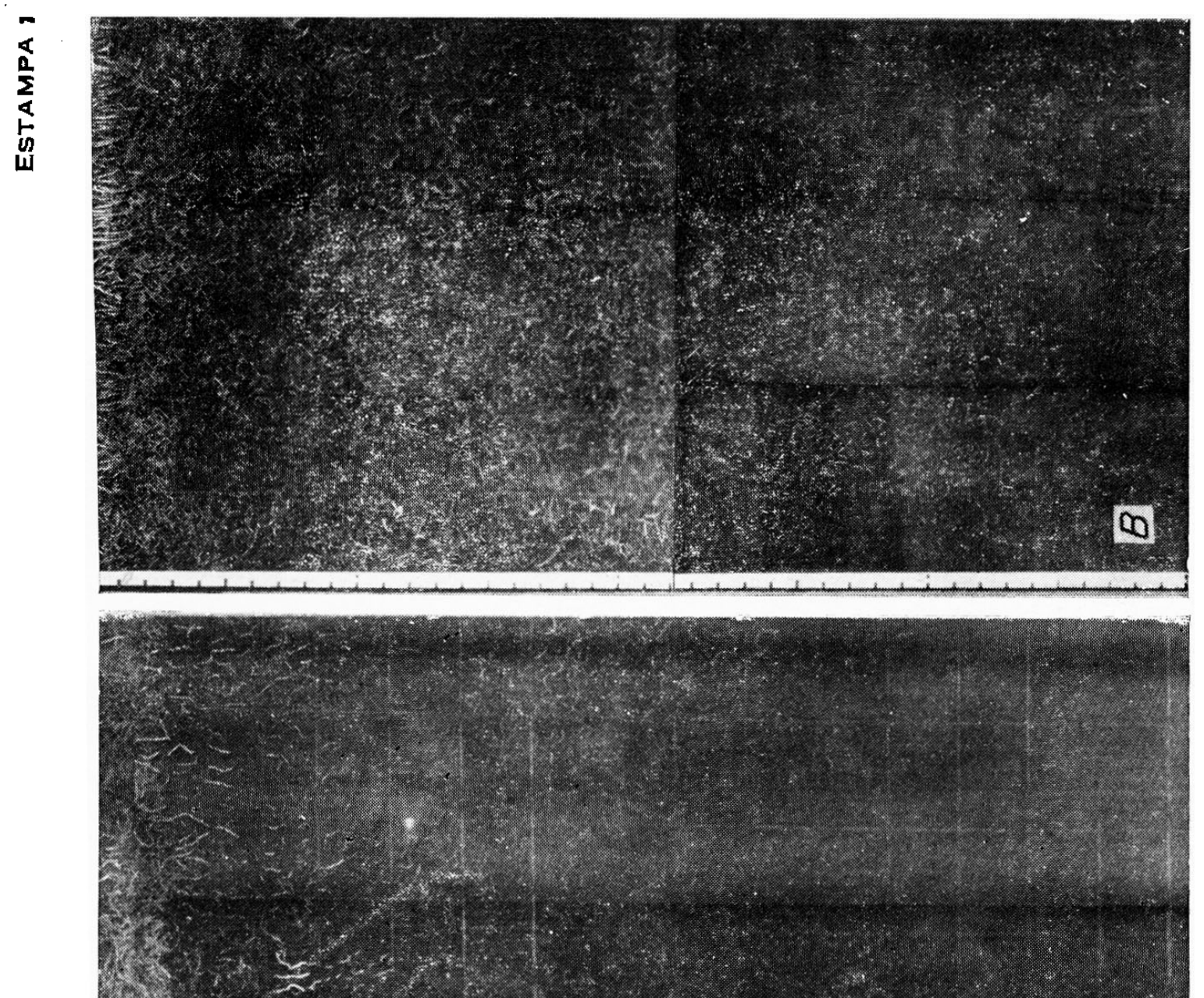

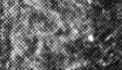 \\ 362}

$2=$

20.

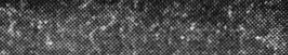

\section{nes}

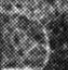

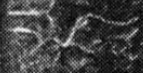

42

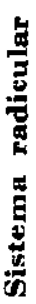



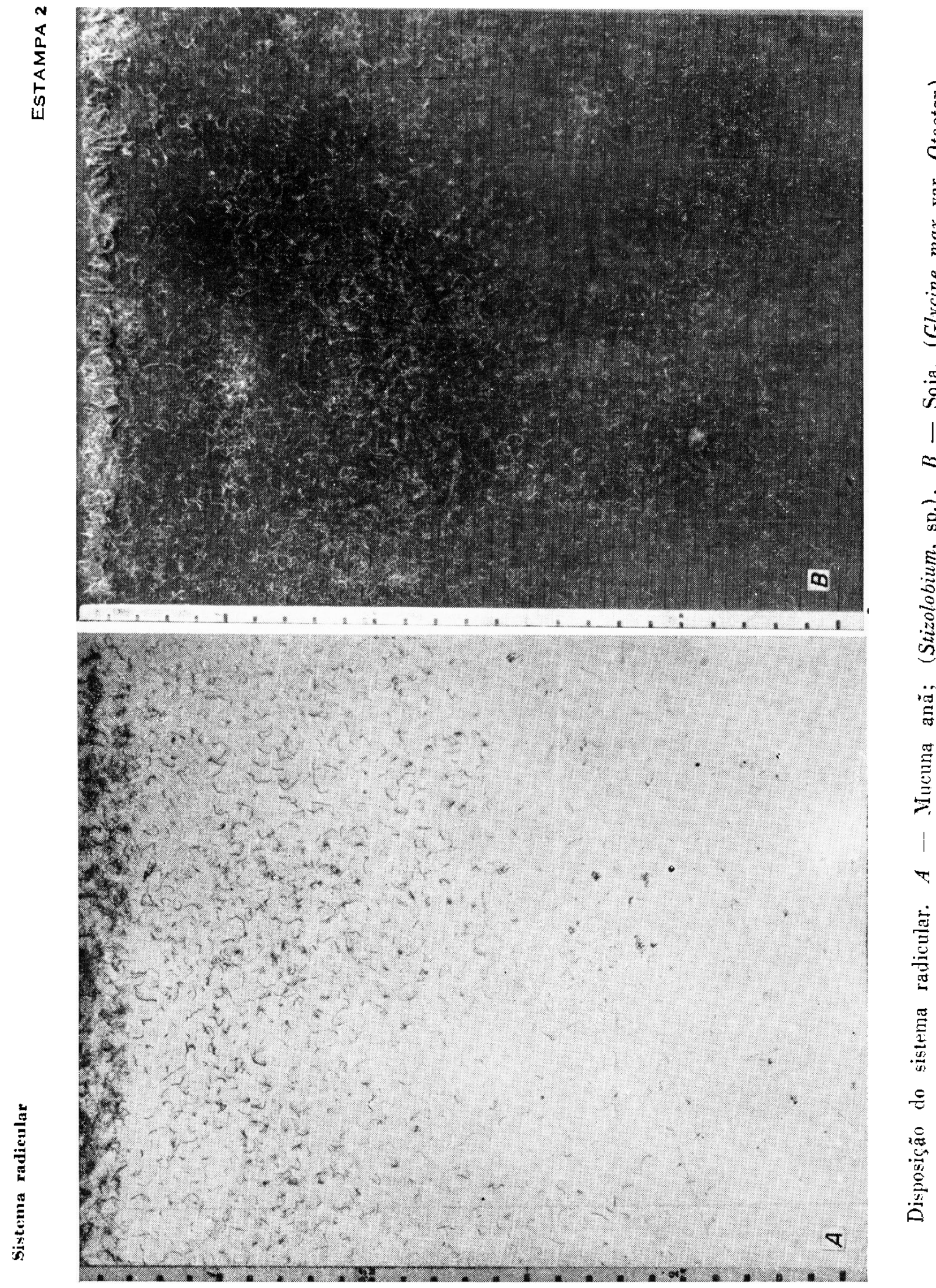